\title{
Vitamin D status of newborns in New Zealand
}

\author{
Carlos A. Camargo, Jr ${ }^{1,2}$, Tristram Ingham ${ }^{3}$, Kristin Wickens ${ }^{3}$, Ravi I. Thadhani ${ }^{2}$, Karen M. Silvers ${ }^{4}$, \\ Michael J. Epton ${ }^{4}$, G. Ian Town ${ }^{5}$, Janice A. Espinola ${ }^{1}$, Julian Crane ${ }^{3}$ and the New Zealand Asthma \\ and Allergy Cohort Study Group \\ ${ }^{1}$ Department of Emergency Medicine, Massachusetts General Hospital, Harvard Medical School, 326 Cambridge Street, Suite 410, \\ Boston, MA 02114, USA \\ ${ }^{2}$ Center for D-receptor Activation Research, Massachusetts General Hospital, Harvard Medical School, Boston, MA, USA \\ ${ }^{3}$ Wellington Asthma Research Group, Department of Medicine, Wellington School of Medicine and Health Sciences, University of \\ Otago, Wellington, New Zealand \\ ${ }^{4}$ Canterbury Respiratory Research Group, Department of Medicine, Christchurch School of Medicine, University of Otago, \\ Christchurch, New Zealand \\ ${ }^{5}$ University of Canterbury, Christchurch, New Zealand \\ (Received 2 December 2009 - Revised 25 March 2010 - Accepted 1 April 2010 - First published online 29 April 2010)
}

Recognition of the important non-skeletal health effects of vitamin D has focused attention on the vitamin D status of individuals across the lifespan. To examine the vitamin D status of newborns, we measured serum levels of 25-hydroxyvitamin D (25(OH)D) in the cord blood of 929 apparently healthy newborns in a population-based study in New Zealand, a country at $41^{\circ} \mathrm{S}$ latitude, with strong anti-skin cancer (sun avoidance) campaigns and without vitamin D food fortification. Randomly selected midwives in two regions recruited children. The median cord blood level of $25(\mathrm{OH}) \mathrm{D}$ was $44 \mathrm{nmol} / \mathrm{l}$ (interquartile range, $29-78 \mathrm{nmol} / \mathrm{l})$. Overall, $19 \%$ of newborns had $25(\mathrm{OH}) \mathrm{D}$ levels $<25 \mathrm{nmol} / \mathrm{l}$ and $57 \%$ had levels $<50 \mathrm{nmol} / 1$; only $27 \%$ had levels of $75 \mathrm{nmol} / 1$ or higher, which are levels associated with optimal health in older children and adults. A multivariable ordinal logistic regression model showed that the strongest determinants of low vitamin D status were winter month of birth and non-European ethnicity. Other determinants of low cord blood $25(\mathrm{OH}) \mathrm{D}$ included longer gestational age, younger maternal age and a parental history of asthma. In summary, low levels of vitamin D are common among apparently healthy New Zealand newborns, and are independently associated with several easily identified factors. Although the optimal timing and dosage of vitamin D supplementation require further study, our findings may assist future efforts to correct low levels of $25(\mathrm{OH}) \mathrm{D}$ among New Zealand mothers and their newborn children.

Vitamin D: 25-Hydroxyvitamin D: Newborns: Pregnancy: New Zealand

Nutritional interventions in pregnancy and early childhood have had a major impact on a variety of maternal and child health problems ${ }^{(1)}$. The potential benefits of vitamin D supplementation in pregnancy and early childhood are less clear $^{(2)}$. Although vitamin D status has important implications for the long-term bone health of the pregnant mother, it actually may have more important implications for the general health of the developing fetus and newborn child. Over the past decade, numerous studies have reported on the myriad health effects of vitamin $\mathrm{D}$ in adults and, increasingly, in children $^{(3)}$. The most promising findings in early childhood are vitamin D-associated increases in growth $^{(4)}$, as well as inverse associations with type 1 diabetes $^{(5)}$ and early childhood wheezing ${ }^{(6,7)}$. Nevertheless, the population prevalence of vitamin D deficiency among newborns - and therefore its public health importance - remains unclear.
Based largely on the historical efforts to prevent rickets, the US Institute of Medicine recommends a dietary reference intake for pregnant women $(5 \mu \mathrm{g} / \mathrm{d})$ that is the same as that recommended for all individuals from birth to the age of 50 years $^{(8)}$. Because of the possible health risk of low vitamin $\mathrm{D}$ status and emerging evidence that populations at higher latitudes are at increased risk of vitamin D deficiency $^{(3)}$, some groups have begun to advocate for higher doses of vitamin D supplementation during pregnancy and early childhood. For example, the Canadian Paediatric Society recently increased their recommendation to up to $50 \mu \mathrm{g} / \mathrm{d}$ for pregnant women and at least $10 \mu \mathrm{g} / \mathrm{d}$ for infants ${ }^{(9)}$. The characteristics of newborns at increased risk of vitamin D deficiency are uncertain, but they are assumed to mirror the risk factors in other age groups (e.g. winter months at high latitude and increased skin pigmentation).

Abbreviation: 25(OH)D, 25-hydroxyvitamin D.

* Corresponding author: Dr Carlos A. Camargo, fax +1 617724 4050, email ccamargo@partners.org 
New Zealand provides an interesting location to examine 'latent' vitamin D deficiency, given its high average latitude $\left(41^{\circ} \mathrm{S}\right)$, strong anti-skin cancer (sun avoidance) campaigns and absence of vitamin D food fortification. The sun avoidance campaign is motivated by one of the highest cutaneous malignant melanoma rates in the world ${ }^{(10)}$, along with concerns about periods of ozone depletion and resulting increases in UV radiation exposure ${ }^{(11)}$. In this context, the New Zealand Ministry of Health defines an adequate intake for pregnant women as $5 \mu \mathrm{g} / \mathrm{d}$, which is the same as that for adults in general $^{(12)}$. Although data are limited, the vast majority of New Zealand women do not take vitamin D supplements during pregnancy. Indeed, a recent survey suggests that only $28-33 \%$ of pregnant women in New Zealand take any type of dietary supplement (e.g. folate) during months 4-7 of their pregnancy ${ }^{(13)}$. Paediatric data are also limited, but an Auckland study of children aged 6-23 months ${ }^{(14)}$ and a national survey of New Zealand children aged 5-14 years found that a substantial number of New Zealand children are vitamin D deficient. To date, the vitamin D status of New Zealand newborns has not been reported.

To address this gap in the literature, we measured serum levels of 25-hydroxyvitamin D $(25(\mathrm{OH}) \mathrm{D})$ in the cord blood of 929 apparently healthy New Zealand newborns to determine their vitamin D status. Having documented a high prevalence of vitamin D deficiency (defined as either $<25$ or $<50 \mathrm{nmol} / \mathrm{l}$ ), we then examined factors that independently predicted vitamin D status at birth.

\section{Experimental methods}

\section{Study design and subjects}

The New Zealand Asthma and Allergy Cohort Study is a prospective birth cohort comprising 1105 infants recruited in Wellington $\left(41^{\circ} \mathrm{S}\right)$ and Christchurch $\left(43^{\circ} \mathrm{S}\right)$ between 1997 and 2001. Briefly, expectant mothers were recruited by a random sample of midwives, health professionals who provide almost all maternity care in New Zealand. At birth, midwives or study nurses collected the newborn's anthropometric details and cord blood, when available. Study nurses conducted face-to-face, structured interviews shortly after birth and at 3 months. Full details of recruitment and follow-up have been presented elsewhere ${ }^{(15)}$. The present study was conducted according to the guidelines laid down in the Declaration of Helsinki, and all procedures involving human subjects were approved by the Wellington and Canterbury Regional Ethics Committees. Written informed consent was obtained from each mother.

Cord blood 25-hydoxyvitamin D. The primary outcome for the present study is the cord blood level of $25(\mathrm{OH}) \mathrm{D}$. Cord blood was available for 929 participants (84\% of the original cohort), and this sample is representative of the overall study population (data not shown). The cord blood samples were promptly refrigerated at $-4^{\circ} \mathrm{C}$ and then transferred, within $24 \mathrm{~h}$, to $-80^{\circ} \mathrm{C}$ freezers for long-term storage. Levels of $25(\mathrm{OH}) \mathrm{D}$ were measured using the LIAISON automated chemiluminescence immunoassay (DiaSorin Stillwater, MN, USA). The assay has an intra-assay CV of $9 \%$ and an interassay CV of $11 \%$. The 929 specimens were run in one batch, sorted by study identification number.
Risk factors. Exposures of interest included study site (Wellington and Christchurch), gestational age, sex, child's ethnicity (European, Māori, Pacific and Other), birth weight, month of birth, season of birth, maternal age at birth and parental history of asthma (neither and either). Child's ethnicity was assessed with the following question: 'Which ethnic group or groups does (child's name) belong to?' For analytical purposes, a child's ethnicity was assigned using the following prioritisation: New Zealand Māori $>$ non-Māori Pacific Islander $>$ Other $>$ European. Socio-economic status was assessed using the New Zealand Deprivation Index 2001 based on the child's home address at 3 months ${ }^{(16)}$; the index ranges from 1 (affluent) to 10 (poor).

\section{Data analysis}

We performed all the analyses using STATA 10.0 (Stata Corporation, College Station, TX, USA). The sample was described using proportions, and means and standard deviations (or medians with interquartile range, where appropriate). For outcome analyses, we generated an ordinal variable from serum $25(\mathrm{OH}) \mathrm{D}$ concentrations to describe vitamin $\mathrm{D}$ status in four groups: $<25,25-49,50-74$ and $75+\mathrm{nmol} / \mathrm{l}$. Unadjusted associations between various newborn and parental characteristics and vitamin D status were examined. For each characteristic, we reported the median $25(\mathrm{OH}) \mathrm{D}$ concentration, interquartile range and the proportion of newborns by vitamin $\mathrm{D}$ status. To test for the trend in vitamin D status for each characteristic, we used the STATA command nptrend, a non-parametric test for trend based on the Wilcoxon-Mann-Whitney test. To adjust for potentially confounding effects of covariates, we created a multivariable ordinal logistic regression model using the four-level vitamin D status variable as the dependent variable. Re-analyses of the data - using data-derived quartiles or a multivariable logistic regression to examine predictors of vitamin $\mathrm{D}$ deficiency per se (serum $25(\mathrm{OH}) \mathrm{D}$ either $<25$ or $<50 \mathrm{nmol} / \mathrm{l}$ ) - yielded similar results (data not shown). A two-tailed $P<0.05$ was considered statistically significant.

\section{Results}

Among the 929 mother-child pairs, midwives recruited 474 pairs $(51 \%)$ in the Wellington area and 455 pairs (49\%) in the Christchurch area. All mothers received free prenatal care from government-supported midwives. Use of prenatal vitamins was not consistently recorded by the study personnel, but was, with the possible exception of folate, uncommon. In the small subset of women taking a daily multivitamin in 1997-2001, most preparations would have contained a maximum of $5 \mu \mathrm{g}$ of vitamin D.

Although 929 mothers consented to participate in the study and provided cord blood for analyses, 7 mothers did not provide baseline data (e.g. demographic factors) at the postnatal visit, leaving 922 newborns in most analyses. Moreover, additional baseline data (e.g. home address and parental history of asthma) were collected at 3 months, at which point, another forty women dropped out of the study. Therefore, the analytical sample size for multivariable models included a maximum of 882 newborns (i.e. $80 \%$ of the original cohort and $95 \%$ of the cohort with cord blood $25(\mathrm{OH}) \mathrm{D}$ levels). 
Table 1. Characteristics of New Zealand newborns by cord blood 25-hydroxyvitamin D concentration (Medians, interquartile ranges (IQR) and percentages, $n$ 929)

\begin{tabular}{|c|c|c|c|c|c|c|c|c|}
\hline & \multirow[b]{3}{*}{$n$} & \multirow[b]{3}{*}{ Median } & \multirow[b]{3}{*}{ IQR } & \multicolumn{4}{|c|}{ Serum 25-hydoxyvitamin D (nmol/l) } & \multirow[b]{3}{*}{$P$ for trend } \\
\hline & & & & $<25(n 180)$ & $25-49$ (n 350) & $50-74(n 146)$ & $75+(n 253)$ & \\
\hline & & & & \multicolumn{4}{|c|}{ Newborns (\%; by row) } & \\
\hline \multicolumn{9}{|l|}{ Study site } \\
\hline Wellington & 474 & 45 & 31,79 & 18 & 37 & 17 & 28 & \\
\hline Christchurch & 455 & 42 & 27,77 & 21 & 38 & 14 & 26 & 0.12 \\
\hline \multicolumn{9}{|l|}{ Gestational age (weeks) } \\
\hline$<37$ & 27 & 64 & 35,90 & 0 & 33 & 26 & 41 & \\
\hline $37-39$ & 335 & 47 & 30,83 & 17 & 36 & 18 & 29 & \\
\hline $40+$ & 555 & 41 & 28,76 & 22 & 39 & 14 & 25 & 0.01 \\
\hline Missing & 12 & 51 & 38,85 & & & & & \\
\hline \multicolumn{9}{|l|}{ Sex } \\
\hline Male & 467 & 44 & 30,80 & 18 & 37 & 18 & 27 & \\
\hline Female & 455 & 44 & 27,78 & 21 & 38 & 14 & 27 & 0.22 \\
\hline Missing & 7 & 53 & 39,99 & & & & & \\
\hline \multicolumn{9}{|l|}{ Ethnicity } \\
\hline European & 655 & 47 & 31,83 & 16 & 36 & 16 & 31 & \\
\hline Māori & 130 & 41 & 27,64 & 21 & 45 & 13 & 22 & \\
\hline Pacific & 54 & 32 & 19,47 & 39 & 39 & 9 & 13 & \\
\hline Other & 43 & 31 & 21,63 & 33 & 33 & 19 & 16 & $<0.001$ \\
\hline Missing & 47 & 42 & 25,63 & & & & & \\
\hline \multicolumn{9}{|l|}{ Birth weight (kg) } \\
\hline$<3$ & 76 & 44 & 30,77 & 21 & 33 & 18 & 28 & \\
\hline $3-3.9$ & 543 & 46 & 30,80 & 18 & 36 & 17 & 28 & \\
\hline $4+$ & 154 & 41 & 26,80 & 21 & 40 & 10 & 29 & 0.50 \\
\hline Missing & 156 & 41 & 29,71 & & & & & \\
\hline Month of birth & & & & & & & & \\
\hline January & 46 & 84 & 45,123 & 2 & 28 & 11 & 59 & \\
\hline February & 60 & 98 & 82,121 & 5 & 10 & 7 & 78 & \\
\hline March & 58 & 81 & 52,124 & 3 & 16 & 24 & 57 & \\
\hline April & 63 & 63 & 38,95 & 8 & 29 & 21 & 43 & \\
\hline May & 72 & 50 & 36,81 & 14 & 36 & 19 & 31 & \\
\hline June & 75 & 35 & 23,48 & 27 & 51 & 15 & 8 & \\
\hline July & 94 & 33 & 20,48 & 38 & 40 & 10 & 12 & \\
\hline August & 110 & 30 & 22,41 & 36 & 49 & 10 & 5 & \\
\hline September & 111 & 35 & 22,51 & 30 & 45 & 14 & 11 & \\
\hline October & 99 & 40 & 26,57 & 20 & 51 & 14 & 15 & \\
\hline November & 74 & 52 & 35,77 & 8 & 39 & 26 & 27 & \\
\hline December & 60 & 68 & 42,90 & 7 & 27 & 23 & 43 & $<0.001$ \\
\hline Missing & 7 & 53 & 39,99 & & & & & \\
\hline Season of birth & & & & & & & & \\
\hline Spring (September-November) & 284 & 39 & 26,60 & 21 & 45 & 17 & 17 & \\
\hline Summer (December-February) & 166 & 85 & 49,111 & 5 & 21 & 14 & 60 & \\
\hline Autumn (March-May) & 193 & 65 & 41,100 & 9 & 27 & 21 & 42 & \\
\hline Winter (June-August) & 279 & 32 & 22,45 & 34 & 47 & 11 & 8 & $<0.001$ \\
\hline Missing & 7 & 53 & 39,99 & & & & & \\
\hline NZ Deprivation Index & & & & & & & & \\
\hline 1 & 156 & 53 & 32,94 & 15 & 30 & 19 & 36 & \\
\hline 2 & 86 & 52 & 33,88 & 16 & 31 & 21 & 31 & \\
\hline 3 & 108 & 41 & 29,69 & 20 & 42 & 18 & 20 & \\
\hline 4 & 114 & 43 & 31,78 & 17 & 43 & 15 & 25 & \\
\hline 5 & 76 & 44 & 31,90 & 11 & 49 & 9 & 32 & \\
\hline 6 & 78 & 44 & 25,78 & 26 & 32 & 10 & 32 & \\
\hline 7 & 63 & 40 & 29,68 & 17 & 46 & 16 & 21 & \\
\hline 8 & 63 & 42 & 25,82 & 25 & 33 & 14 & 27 & \\
\hline 9 & 77 & 48 & 27,79 & 22 & 31 & 19 & 27 & \\
\hline 10 & 61 & 36 & 23,48 & 30 & 46 & 10 & 15 & 0.001 \\
\hline Missing & 47 & 42 & 25,63 & & & & & \\
\hline Maternal age at birth (years) & & & & & & & & \\
\hline$<30$ & 409 & 40 & 26,70 & 23 & 41 & 14 & 22 & \\
\hline $30-34$ & 358 & 49 & 31,87 & 17 & 34 & 17 & 32 & \\
\hline $35-39$ & 121 & 43 & 31,76 & 18 & 39 & 17 & 26 & \\
\hline $40+$ & 24 & 58 & 36,83 & 4 & 42 & 21 & 33 & 0.15 \\
\hline Missing & 17 & 53 & 39,93 & & & & & \\
\hline Parental history of asthma & & & & & & & & \\
\hline Neither & 650 & 46 & 30,81 & 18 & 37 & 15 & 30 & \\
\hline Either & 172 & 41 & 26,69 & 23 & 41 & 17 & 19 & 0.03 \\
\hline Missing & 107 & 41 & 27,71 & & & & & \\
\hline
\end{tabular}

NZ, New Zealand. 
As noted in Methods section, the sample was population based without any specific exclusion criteria. As expected, most newborns were term, with a median gestational age of 40 (interquartile range, 39-41) weeks and a mean birth weight of 3.6 (SD 0.5) $\mathrm{kg}$. Mean maternal age at birth was 30 (SD 5) years. A slightly higher proportion of children were born during the spring (September-November, 31\%) and winter (June-August, 30\%) months. The majority of newborns were of European ethnicity $(71 \%)$, but the major minority groups of New Zealand also were represented, with $14 \%$ being Māori and $6 \%$ of Pacific ethnicity. Newborns of 'Other' ethnicity (5\%) were predominantly Asian (34 of 43, or $79 \%$ ). Thus, the racial/ethnic mix of the cohort closely matches that of the overall New Zealand population ${ }^{(15)}$.

Participants had a median cord blood $25(\mathrm{OH}) \mathrm{D}$ concentration of $44 \mathrm{nmol} / 1$ (interquartile range, $29-78 \mathrm{nmol} / \mathrm{l}$ ). Overall, $19 \%$ of New Zealand newborns had serum 25(OH)D levels $<25 \mathrm{nmol} / 1$ and $57 \%$ had levels $<50 \mathrm{nmol} / 1$; only $27 \%$ had the $25(\mathrm{OH}) \mathrm{D}$ levels of $75 \mathrm{nmol} / \mathrm{l}$ or higher. Table 1 shows the associations between various newborn and parental characteristics and vitamin D status. Looking across the four categories of $25(\mathrm{OH}) \mathrm{D}$, the median $25(\mathrm{OH}) \mathrm{D}$ values were $19,36,60$ and $100 \mathrm{nmol} / \mathrm{l}$, respectively. The unadjusted associations between the various characteristics and vitamin D status were strongest for newborn ethnicity and month (season) of birth (all $P$ for trend $\leq 0.001$ ). As expected, median serum $25(\mathrm{OH}) \mathrm{D}$ concentrations peaked in infants born during summer months, and were lowest for infants born in the winter. Unadjusted analyses also indicated that gestational age, New Zealand Deprivation Index and parental history of asthma were potential determinants of newborn vitamin D status (all $P$ for trend $<0.05$ ).

The newborns of Pacific ethnicity and 'Other' (i.e. nonEuropean, non-Māori and non-Pacific) ethnicity had the lowest median 25(OH)D serum concentrations, with values of 32 and $31 \mathrm{nmol} / \mathrm{l}$, respectively. Indeed, a clear majority of newborns of Pacific ethnicity $(78 \%)$ and Other ethnicity $(66 \%)$ had cord blood 25(OH)D levels $<50$ nmol/l. Twothirds of Māori newborns also had 25(OH)D levels $<50 \mathrm{nmol} / \mathrm{l}$, though Māori children were less likely than the other non-European groups to have levels $<25 \mathrm{nmol} / \mathrm{l}$.

Adjusting for multiple newborn and parental characteristics (including socio-economic status), month of birth and ethnicity remained the strongest determinants of vitamin D status (Table 2). Newborns born in October through May were more likely to have a higher vitamin D status than those born in August (all $P \leq 0 \cdot 001$ ). Those born in February, the final summer month, were sixty-seven times more likely to have a higher vitamin D status than those born in August. Compared with newborns of European ethnicity, newborns of Pacific ethnicity were $77 \%$ less likely to have a higher vitamin D status, while those of Other ethnicity were $75 \%$ less likely to have a higher vitamin $\mathrm{D}$ status (both $P<0.001$ ). Those of Māori ethnicity also seemed less likely to have a higher vitamin $\mathrm{D}$ status, but the estimate was not statistically significant $(P=0 \cdot 06)$.

New Zealand newborns with a gestational age of 40 or more weeks were less likely to have a higher vitamin D status than those born between 37 and 39 weeks. Newborns with older mothers, particularly those over 40 years of age, were more likely to have a higher vitamin D status than newborns
Table 2. Multivariable ordinal logistic regression model of higher cord blood 25-hydroxyvitamin D concentrations

(Odds ratios and $95 \%$ confidence intervals, $n 744$ with complete data)

\begin{tabular}{|c|c|c|c|}
\hline Characteristics & OR & $95 \% \mathrm{Cl}$ & $P$ \\
\hline \multicolumn{4}{|l|}{ Study site } \\
\hline Wellington & Reference & & - \\
\hline Christchurch & 0.84 & $0.62,1.14$ & 0.27 \\
\hline \multicolumn{4}{|l|}{ Gestational age (weeks) } \\
\hline$<37$ & 1.74 & $0.60,5.07$ & 0.31 \\
\hline $37-39$ & Reference & & - \\
\hline $40+$ & 0.68 & $0.50,0.92$ & 0.01 \\
\hline \multicolumn{4}{|l|}{ Sex } \\
\hline Male & Reference & & - \\
\hline Female & 0.78 & $0.59,1.04$ & 0.09 \\
\hline \multicolumn{4}{|l|}{ Ethnicity } \\
\hline European & Reference & & - \\
\hline Māori & 0.66 & $0.43,1.01$ & 0.06 \\
\hline Pacific & 0.23 & $0.12,0.45$ & $<0.001$ \\
\hline Other & 0.25 & $0.12,0.50$ & $<0.001$ \\
\hline Birth weight (kg) & 0.80 & $0.58,1.09$ & 0.16 \\
\hline \multicolumn{4}{|l|}{ Month of birth } \\
\hline January & $22 \cdot 27$ & $10 \cdot 23,48 \cdot 47$ & $<0.001$ \\
\hline February & $67 \cdot 11$ & $28.68,156.99$ & $<0.001$ \\
\hline March & $26 \cdot 19$ & $12 \cdot 04,56 \cdot 95$ & $<0.001$ \\
\hline April & $17 \cdot 39$ & $8.44,35.83$ & $<0.001$ \\
\hline May & 5.98 & $3.16,11 \cdot 32$ & $<0.001$ \\
\hline June & 1.96 & $1.06,3.63$ & 0.03 \\
\hline July & 1.49 & $0.82,2.73$ & $0 \cdot 19$ \\
\hline August & Reference & & - \\
\hline September & 1.59 & $0.89,2.84$ & 0.12 \\
\hline October & $2 \cdot 67$ & $1.49,4.80$ & 0.001 \\
\hline November & $6 \cdot 60$ & $3 \cdot 57,12 \cdot 18$ & $<0.001$ \\
\hline December & $12 \cdot 48$ & $6 \cdot 31,24 \cdot 67$ & $<0.001$ \\
\hline NZ Deprivation Index & 0.97 & $0.92,1.03$ & 0.30 \\
\hline \multicolumn{4}{|c|}{ Maternal age at birth (years) } \\
\hline$<30$ & Reference & & - \\
\hline $30-34$ & 1.62 & $1 \cdot 18,2 \cdot 22$ & 0.003 \\
\hline $35-39$ & 1.18 & $0.73,1.88$ & 0.50 \\
\hline $40+$ & $2 \cdot 68$ & $1 \cdot 06,6 \cdot 77$ & 0.04 \\
\hline \multicolumn{4}{|c|}{ Parental history of asthma } \\
\hline Neither & Reference & & - \\
\hline Either & 0.70 & $0.53,0.94$ & 0.02 \\
\hline
\end{tabular}

NZ, New Zealand.

with younger mothers (age $<30$ years). Also, those born to a parent with a history of asthma were less likely to have a higher vitamin D status. Parental histories of allergic rhinitis or eczema were NS predictors of newborn $25(\mathrm{OH}) \mathrm{D}$ levels (data not shown). Other factors that were NS predictors of vitamin D status, after adjusting for covariates, were study site, sex, birth weight and New Zealand Deprivation Index.

\section{Discussion}

In a population-based cohort of 929 apparently healthy New Zealand children, we found that cord blood levels of $25(\mathrm{OH}) \mathrm{D}$ were generally quite low. Almost one in five children started life with $25(\mathrm{OH}) \mathrm{D}$ levels $<25 \mathrm{nmol} / \mathrm{l}$. Cord blood 25(OH)D had strong associations with a summer birth, which was the single strongest predictor of high vitamin D status. Significant predictors of low cord blood 25(OH)D were non-European ethnicity, longer gestational age, younger maternal age and parental history of asthma.

The seasonality of serum 25(OH)D levels in older children and adults is well documented ${ }^{(14,17-19)}$. By contrast, few studies 
have examined this issue in the newborn children. In recent years, vitamin D deficiency in newborns has been reported in several developing nations, such as $\operatorname{India}^{(20)}$ and $\operatorname{Iran}^{(21)}$. Of greater relevance to our New Zealand cohort, investigators in Sydney, Australia $\left(33^{\circ} \mathrm{S}\right)$, recently reported that vitamin D deficiency (defined as $<25 \mathrm{nmol} / \mathrm{l}$ ) was found in $15 \%$ of pregnant women and $11 \%$ of newborns ${ }^{(22)}$. At more comparable latitudes in the USA, investigators in Pittsburgh $\left(40^{\circ} \mathrm{N}\right)$ reported vitamin $\mathrm{D}$ deficiency (defined as $25(\mathrm{OH}) \mathrm{D}<37.5$ $\mathrm{nmol} / \mathrm{l}$ ) in $10 \%$ of white newborns and $47 \%$ of black newborns in a sample of 400 mother-child pairs ${ }^{(23)}$. Similar results were reported from Boston $\left(42^{\circ} \mathrm{N}\right)$, where $80 \%$ of newborns had $25(\mathrm{OH}) \mathrm{D}<50 \mathrm{nmol} / 1$ despite seemingly ample intake of vitamin D by their mothers (e.g. $70 \%$ took daily prenatal vitamin of $10 \mu \mathrm{g}, 90 \%$ of the sample ate fish and $93 \%$ drank approximately 2.3 glasses of vitamin D-fortified milk daily) ${ }^{(24)}$. A study of 123 healthy motherchild pairs in Athens, Greece $\left(38^{\circ} \mathrm{N}\right)$, found that vitamin D deficiency (defined as $<25 \mathrm{nmol} / \mathrm{l}$ ) was present in $20 \%$ of pregnant women and $8 \%$ of newborns ${ }^{(25)}$. We are not aware of prior studies that have examined how seasonal patterns of cord blood $25(\mathrm{OH}) \mathrm{D}$ might differ between the ethnic populations of New Zealand. The low 25(OH)D levels of Pacific newborns raise significant concerns for this important and growing segment of the New Zealand population.

At a minimum, our data suggest that New Zealand women should consider vitamin D supplements during the late autumn and winter to offset their likely decline in vitamin $\mathrm{D}$ during these months with less UVB exposure. The optimal timing and dosage of maternal vitamin $\mathrm{D}$ remain unknown, with most groups recommending $5 \mu \mathrm{g} / \mathrm{d}^{(8)}$ but others recommending up to $50 \mu \mathrm{g} / \mathrm{d}^{(9)}$. A recently completed trial of pregnant women in South Carolina provided even higher doses $(100 \mu \mathrm{g} / \mathrm{d})$ throughout pregnancy, and this regimen did not appear to have caused any measurable harm (B. Hollis, personal communication). Nevertheless, others have appropriately cautioned against the use of seemingly high doses of vitamin D without better safety data ${ }^{(26)}$. Clearly, there is an urgent need for further research in this novel area of human nutrition.

The lower vitamin D levels of dark-skinned individuals also are consistent with prior reports among older children and adults $^{(3)}$. Skin pigment interferes with vitamin D synthesis in the skin, and it has been estimated that dark-skinned individuals require to spend five to ten times as long in the sunlight to create the same amount of vitamin D as their light-skinned counterparts ${ }^{(27)}$. To date, there are very sparse data on the vitamin D status of the Māori and Pacific children of New Zealand. The only other published work on this topic, among New Zealand children aged 6-23 months ${ }^{(14)}$ and aged 5-14 years $^{(18)}$, also found that the highest prevalence of vitamin D deficiency was among Pacific, rather than among Māori, children. Our study extends this finding to newborns, and demonstrates that this difference is independent of several pregnancy-related and socio-economic factors. Although skin pigmentation is the most likely explanation for the observed ethnic differences, the contribution of other genetic or environmental differences merits further study.

The other independent correlates of low vitamin D status included longer gestational age, younger maternal age and parental history of asthma. We lack data on gestational diabetes, but note that this condition is associated with longer gestational age and may be more common in mothers with vitamin D deficiency ${ }^{(28)}$. Moreover, a longer gestational age might provide further opportunity for the developing fetus to draw upon a mother's depleted reserves - a scenario that argues against a single dietary reference intake for pregnant and non-pregnant women alike ${ }^{(8)}$. It is more difficult to explain the maternal age finding. Were younger mothers more likely to comply with sun avoidance or less likely to take prenatal vitamins? We believe that this finding requires replication and further study. The same is true of the association between parental history of asthma and lower cord blood levels of $25(\mathrm{OH}) \mathrm{D}$. Confirmatory results would be of likely relevance to recent reports of an inverse association between vitamin $\mathrm{D}$ status and several asthma-related outcomes $^{(6,7,29)}$.

What is the health impact of low cord blood levels of $25(\mathrm{OH}) \mathrm{D}$ ? To date, the paucity of outcome data prevents any definitive statements, but there is a growing international interest in this issue. In recent years, the European and North American investigators have found higher risk of several important childhood diseases among those with low vitamin $\mathrm{D}$ status, including type 1 diabetes ${ }^{(5)}$, wheezing ${ }^{(6,7)}$ and winter-related eczema ${ }^{(30)}$. As research advances on the role of vitamin D in pregnancy and early childhood, evidence about health outcomes will surely grow. These future studies will provide data to better inform healthcare providers and public health officials about what exactly constitutes vitamin $\mathrm{D}$ 'deficiency' in newborns, as well as the levels that are associated with optimal health.

Another research need suggested by our work is the development of an equation to link the more easily tested maternal level of $25(\mathrm{OH}) \mathrm{D}$ with the expected level of a child at birth. Unfortunately, we did not measure concurrent maternal $25(\mathrm{OH}) \mathrm{D}$ levels, and are unable to examine this issue. Vitamin D metabolites, especially $25(\mathrm{OH}) \mathrm{D}$, are known to cross the placenta ${ }^{(31)}$. Prior studies, based on relatively small samples, suggest that maternal levels of $25(\mathrm{OH}) \mathrm{D}$ are approximately $10-15 \mathrm{nmol} / \mathrm{l}$ higher than the levels in cord blood $^{(20,23)}$. By contrast, a study from Greece found significantly lower average levels of $25(\mathrm{OH}) \mathrm{D}$ in 123 term mothers $(41 \mathrm{nmol} / \mathrm{l})$ than in the cord blood $(51 \mathrm{nmol} / \mathrm{l})^{(25)}$. Population-based studies of diverse samples are needed. The development of such an equation would facilitate the development of studies on the potential impact of introducing a maternal supplement during pregnancy or early childhood without the logistical complexity and research challenges of measuring 25(OH)D levels in cord blood.

The present study has other potential limitations. Although the study lacks data on food intake during pregnancy, nonfortified food sources of vitamin $\mathrm{D}$ have limited effect on serum $25(\mathrm{OH}) \mathrm{D}$ levels ${ }^{(3,24)}$. The study also lacks data on maternal $25(\mathrm{OH}) \mathrm{D}$ levels from earlier in the pregnancy; it would have been interesting to examine the relationship of earlier levels with cord blood levels. Although estimates vary, the half-life of serum $25(\mathrm{OH}) \mathrm{D}$ in adults is $2-3$ weeks $^{(8)}$. If this was true in cord blood, it would suggest that the measured levels reflect maternal-fetal status during the final months of pregnancy. Sun-related behaviours and dietary intake may change over the course of a pregnancy, but these changes are relatively minor ${ }^{(32)}$ and probably, they are not influenced 
by baseline levels of maternal $25(\mathrm{OH}) \mathrm{D}$. Thus, we believe that the cord blood values provide a reasonably accurate way to rank-order mothers by their vitamin D status during pregnancy - and, therefore, to identify characteristics of mothers who might benefit from higher dose vitamin D supplementation.

In summary, vitamin D deficiency and insufficiency are common in apparently normal newborns in New Zealand. The health implications of this finding are not clear, but a growing body of evidence suggest that lower levels of vitamin $\mathrm{D}$ are associated with important health problems of childhood. Given the absence of any compelling evidence for an adverse effect of increased vitamin D intake among pregnant women, and with some professional societies already recommending much higher doses ${ }^{(9)}$, we believe that such a public health campaign merits serious consideration. The optimal timing and dosage of vitamin $\mathrm{D}$ supplementation require further study. In the meantime, however, our findings can help identify individuals at increased risk, and thereby assist efforts to correct the low levels of vitamin D among most New Zealand mothers and their newborn children.

\section{Acknowledgements}

We thank the midwives in Wellington, Porirua and Canterbury for their assistance with recruitment, and all the families and children for their participation. The New Zealand Asthma and Allergy Cohort Study Group consisted of J. C., M. Duignan, M. J. E., D. Fishwick, P. Fitzharris, T. I., V. Irvine, R. Kelly, P. Lampshire, J. Lane, P. Leadbitter, C. MacDonald, F. McCartin, S. McLeod, A. Nicholson, P. Pattemore, K. Roff, G. Sawyer, R. Siebers, G. I. T., K. W., H. Wilson and K. Withell. This work was supported by grants from the Health Research Council of New Zealand, the David and Cassie Anderson Bequest (Wellington, New Zealand), and the Massachusetts General Hospital Center for D-receptor Activation Research (Boston, MA, USA). None of the authors has any potential conflicts of interest. The authors' contributions are as follows: C. A. C. had full access to all the data in the study, and takes responsibility for the integrity of the data and the accuracy of the data analysis. C. A. C., G. I. T. and J. C. were involved in the study concept and design. C. A. C., T. I., K. W., R. I. T., M. J. E., G. I. T. and J. C. were involved in the acquisition of data. C. A. C., T. I., K. W., K. M. S., J. A. E. and J. C. were involved in the analysis and interpretation of data. C. A. C. was involved in the preparation of the manuscript. The critical revision of the manuscript for important intellectual content was done by C. A. C., T. I., K. W., R. I. T., K. M. S., M. J. E., G. I. T., J. A. E. and J. C. C.; A. C. and J. A. E. performed the statistical analysis. C. A. C., M. J. E. and J. C. were involved in the study supervision.

\section{References}

1. Anonymous (2009) Women, Infants, and Children (WIC) Website. http://www.fns.usda.gov/wic/ (accessed 11 January 2009).

2. Hollis BW \& Wagner CL (2004) Assessment of dietary vitamin $\mathrm{D}$ requirements during pregnancy and lactation. Am J Clin Nutr 79, 717-726.
3. Holick MF (2007) Vitamin D deficiency. N Engl J Med 357, 266-281.

4. Javaid MK, Crozier SR, Harvey NC, et al. (2006) Maternal vitamin D status during pregnancy and childhood bone mass at age 9 years: a longitudinal study. Lancet 367, 36-43.

5. Hypponen E, Laara E, Reunanen A, et al. (2001) Intake of vitamin D and risk of type 1 diabetes: a birth-cohort study. Lancet 358, 1500-1503.

6. Camargo CA Jr, Rifas-Shiman SL, Litonjua AA, et al. (2007) Maternal intake of vitamin D during pregnancy and risk of recurrent wheeze in children at 3 y of age. Am J Clin Nutr 85, 788-795.

7. Devereux G, Litonjua AA, Turner SW, et al. (2007) Maternal vitamin D intake during pregnancy and early childhood wheezing. Am J Clin Nutr 85, 853-859.

8. Standing Committee on the Scientific Evaluation of Dietary Reference Intakes (1997) Dietary Reference Intakes for Calcium, Phosphorus, Magnesium, Vitamin D, and Fluoride. Washington, DC: Institute of Medicine.

9. Canadian Paediatric Society (2007) Vitamin D supplementation: recommendations for Canadian mothers and infants (Position Statement FNIM 2007-01). Paediatr Child Health 12, 583-589.

10. World Health Organization (2001) GLOBOCAN: Cancer Incidence, Mortality and Prevalence Worldwide, IARC Cancerbase No. 5, Version 1.0. Lyon: IARC.

11. Allan W, Riedel K, McKenzie R, et al. (2009) Atmosphere ozone and ultraviolet radiation. In Te Ara - Encyclopedia of New Zealand. http://www.TeAra.govt.nz/en/atmosphere/4 (accessed 11 January 2009).

12. Ministry of Health (2005) Food and Nutrition Guidelines for Healthy Pregnant and Breastfeeding Women: A Background Paper: Draft for Consultation. Wellington: Ministry of Health.

13. Watson PE \& McDonald B (1999) Nutrition During Pregnancy: A Report to the Ministry of Health. Auckland: Massey University (Albany Campus).

14. Grant CC, Wall CR, Crengle S, et al. (2009) Vitamin D deficiency in early childhood: prevalent in the sunny South Pacific. Public Health Nutr 12, 1893-1901.

15. Epton MJ, Town GI, Ingham T, et al. (2007) The New Zealand Asthma and Allergy Cohort Study (NZA $\left.{ }^{2} \mathrm{CS}\right)$ : assembly, demographics and investigations. BMC Public Health 7, 26.

16. Salmond C \& Crampton P (2001) NZDep2001 Index of Deprivation, User's Manual. Wellington: Department of Public Health, Wellington School of Medicine and Health Sciences.

17. Hanley DA \& Davison KS (2005) Vitamin D insufficiency in North America. J Nutr 135, 332-337.

18. Rockell JE, Green TJ, Skeaff CM, et al. (2005) Season and ethnicity are determinants of serum 25-hydroxyvitamin D concentrations in New Zealand children aged 5-14y. J Nutr 135, 2602-2608.

19. Brot C, Vestergaard P, Kolthoff N, et al. (2001) Vitamin D status and its adequacy in healthy Danish perimenopausal women: relationships to dietary intake, sun exposure and serum parathyroid hormone. Br J Nutr 86, Suppl. 1, S97-103.

20. Sachan A, Gupta R, Das V, et al. (2005) High prevalence of vitamin D deficiency among pregnant women and their newborns in northern India. Am J Clin Nutr 81, 1060-1064.

21. Maghbooli Z, Hossein-Nezhad A, Shafaei AR, et al. (2007) Vitamin D status in mothers and their newborns in Iran. BMC Pregnancy Childbirth 7, 1.

22. Bowyer L, Catling-Paull C, Diamond T, et al. (2009) Vitamin $\mathrm{D}, \mathrm{PTH}$ and calcium levels in pregnant women and their neonates. Clin Endocrinol (Oxf) 70, 372-377.

23. Bodnar LM, Simhan HN, Powers RW, et al. (2007) High prevalence of vitamin D insufficiency in black and white pregnant women residing in the northern United States and their neonates. $J$ Nutr 137, 447-452. 
24. Lee JM, Smith JR, Philipp BL, et al. (2007) Vitamin D deficiency in a healthy group of mothers and newborn infants. Clin Pediatr (Phila) 46, 42-44.

25. Nicolaidou P, Hatzistamatiou Z, Papadopoulou A, et al. (2006) Low vitamin D status in mother-newborn pairs in Greece. Calcif Tissue Int 78, 337-342.

26. Wjst M (2006) The vitamin D slant on allergy. Pediatr Allergy Immunol 17, 477-483.

27. Chen TC, Chimeh F, Lu Z, et al. (2007) Factors that influence the cutaneous synthesis and dietary sources of vitamin D. Arch Biochem Biophys 460, 213-217.

28. Maghbooli Z, Hossein-Nezhad A, Karimi F, et al. (2008) Correlation between vitamin $\mathrm{D}_{3}$ deficiency and insulin resistance in pregnancy. Diabetes Metab Res Rev 24, 27-32.
29. Erkkola M, Kaila M, Nwaru BI, et al. (2009) Maternal vitamin D intake during pregnancy is inversely associated with asthma and allergic rhinitis in 5-year-old children. Clin Exp Allergy 39, $875-882$.

30. Sidbury R, Sullivan AF, Thadhani RI, et al. (2008) Randomized trial of vitamin D supplementation for winter-related atopic dermatitis in Boston: a pilot study. Br J Dermatol 159 , 245-247.

31. Hillman LS \& Haddad JG (1974) Human perinatal vitamin D metabolism. I. 25-Hydroxyvitamin D in maternal and cord blood. J Pediatr 84, 742-749.

32. Rifas-Shiman SL, Rich-Edwards JW, Willett WC, et al. (2006) Changes in dietary intake from the first to the second trimester of pregnancy. Paediatr Perinat Epidemiol 20, 35-42. 